\title{
Innovación docente en el aprendizaje de la Historia del Arte. Diseño, aplicación y resultados de un ciclo de mejora
}

\section{Teaching innovation in the learning of Art History. Design, application and results of an improvement cycle}

MANuel GÁmez CASAdo

ORCID: https://orcid.org/0000-0002-5539-1104

Universidad de Sevilla

Departamento de Historia del Arte

mgamez@us.es

DOI: http://dx.doi.org/10.12795/9788447231003.021

Pp.: 446-465 


\section{Contexto del ciclo de mejora}

El proceso de aprendizaje de la disciplina de la Historia del Arte requiere de una serie de mejoras que permitan innovar en cuestiones relacionadas con la metodología, la elección de contenidos y la evaluación. Precisamente como primer paso para lograr ese desarrollo, se presenta un ciclo de mejora diseñado y aplicado en la asignatura Arte Antiguo y Medieval en Andalucía, cursada dentro del plan de estudio del grado de Historia del Arte ofertado por la Universidad de Sevilla. Con el diseño y aplicación de este ciclo se pretende que el alumno ahonde en dos cuestiones fundamentales para entender las particularidades de la arquitectura romana en el contexto del arte antiguo, como son la relación entre arquitectura y política y los antecedentes y consecuentes de sus tipologías constructivas. Igualmente, la intención es ofrecer un contenido teórico y metodológico diferente al alumno, que debe enfrentarse de manera activa a una serie de actividades programadas para el enriquecimiento de su experiencia académica, personal y profesional como historiador.

Para la aplicación de este ciclo de mejora es necesario que el alumno ahonde en un contexto académico muy determinado, convirtiéndose en este caso en profesionales de la Historia del Arte que deben resolver una serie de cuestiones relacionadas con la investigación, en un papel profesionalizante que en escasas ocasiones se oferta en el conjunto del grado universitario. Así, teniendo en cuenta que la principal labor del historiador es la investigación, se pretende crear un contexto académico en el que el estudiante se sienta identificado con la figura del arqueólogo que debe analizar detalladamente un edificio, obviando cuestiones tradicionales como su clasificación y profundizando en otros asuntos más complejos, tales como sus influencias o modelos tipológicos empleados para su diseño. Este ciclo de mejora complementará al apartado teórico más tradicional, desarrollado en el resto de las clases,

Ciclos de Mejora en el Aula (2020). Experiencias de Innovación Docente de la US Esta obra se distribuye con la licencia Creative Commons 
con la intención de trasladar paulatinamente a los otros temas las actividades aquí propuestas. Todo ello debe servir como punto de partida hacia una nueva metodología docente que cambie la concepción de los estudios en Historia del Arte.

\section{Diseño previo del CIMA}

El ciclo de mejora que se presenta fue aplicado en cuatro clases diferentes entre los días 12 y 20 de noviembre de 2020. En el desarrollo de esas sesiones se abordaron dos problemas fundamentales dentro del tema dedicado a la historia de la arquitectura romana en Andalucía. El primero consistió en resolver ¿cómo se explica la relación existente entre la arquitectura y los distintos sistemas políticos implantados en la antigua Roma?, mientras que en el segundo se planteó ¿cuáles son los antecedentes y consecuentes tipológicos de la arquitectura y el urbanismo romano? A partir de estas dos grandes preguntas se desarrollaron los conceptos propios de proceso de aprendizaje, que tradicionalmente se han organizado sin conocer que el verdadero origen de su desarrollo partía de una cuestión previa. En esta ocasión, el alumno se expone a una primera reflexión sobre una pregunta a resolver para, posteriormente, iniciar un proceso de mejora del conocimiento sobre la materia mediante el aprendizaje de nuevos conceptos, datos, valores y procedimientos que deben mejorar su evaluación final.

\section{Mapa de contenidos}

El diseño del mapa de contenidos incluido en el ciclo de mejora que se presenta parte de las dos cuestiones comentadas en el apartado anterior. Partiendo de un aprendizaje generalizado sobre arquitectura romana, se muestran dos apartados unidos por un eje central en el que se

Ciclos de Mejora en el Aula (2020). Experiencias de Innovación Docente de la US Esta obra se distribuye con la licencia Creative Commons 
inserta el análisis histórico artístico como contenido procedimental y el vocabulario técnico de la disciplina como datos que requieren de una cierta memorización por parte del alumno. En relación a la primera pregunta, se presentan diferentes temas de carácter conceptual y vinculados a la relación existente entre la arquitectura y su contexto como contenido estructural. La segunda de las cuestiones se resuelve mediante la integración tanto de un apartado conceptual y también estructural en el que se desarrollará el análisis de antecedentes y consecuentes de la arquitectura romana, como de otros contenidos actitudinales relacionados con la difusión y conservación de estas obras.

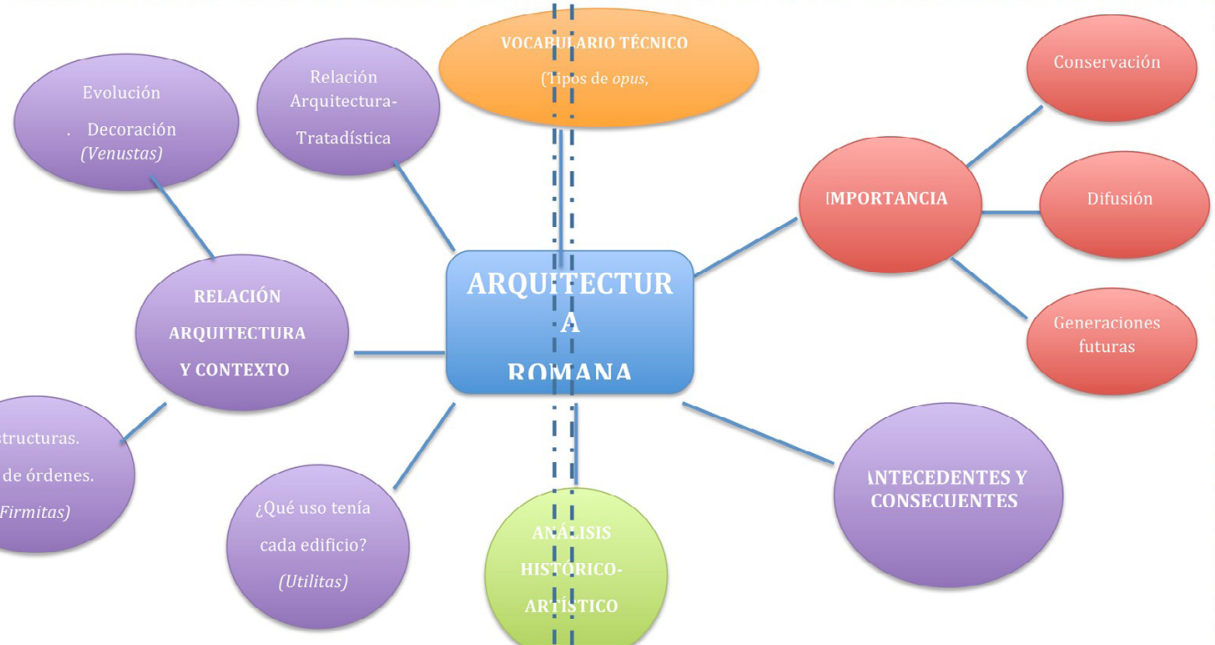

PROBLEMA 1: ¿Cómo se explica la relación existente entre la arquitectura y los distintos sistemas políticos en Roma?

I I PROBLEMA 2: ¿Cuáles son los antecedentes y consecuentes I I tipológicos de la arquitectura y el urbanismo romano?

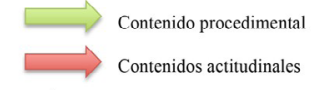

*MAYÚSCULAS: Contenido estructural.

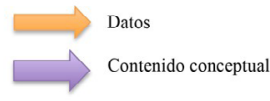

Figura 1: Mapa de contenidos y problemas

Ciclos de Mejora en el Aula (2020). Experiencias de Innovación Docente de la US Esta obra se distribuye con la licencia Creative Commons 

de actividades programadas

El planteamiento del modelo metodológico posible que se presenta debe entenderse como una primera aproximación a un futuro modelo ideal, como meta a alcanzar en próximos ciclos de mejora. La principal intención es aumentar la participación del alumno tanto en el proceso de aprendizaje, como en el propio desarrollo de la sesión. De forma tradicional, los alumnos han asistido a clases basadas en la transmisión del conocimiento por el profesor. Con este modelo se pretende que el alumno asista a la sesión con un mayor conocimiento de la materia a través del análisis de una serie de textos y de la realización de pequeños trabajos en los que deberán resolver distintos problemas históricos planteados con anterioridad. Todo ello generará un mayor conocimiento sobre el contenido de la sesión, así como enriquecedores debates en los que se crucen las hipótesis defendidas por los alumnos, creando una forma diferente de resolver las cuestiones propias de la asignatura.

En otras ocasiones, estas actividades se complementarán con salidas de campo en las que el alumno se enfrentará de forma directa con la obra de arte, debiendo analizarla de primera mano sin necesidad de que el profesor lo haga a través de imágenes. Los conocimientos e hipótesis previas del alumno les servirán para enfrentarse a la tarea de clasificar y analizar los espacios y objetos, resolviendo los problemas estructurales planteados y acercándose a la labor profesional que el historiador del arte hace de forma habitual convencional. Este proceso será completado con actividades de contraste y de exposición de pautas teóricas del profesor relacionadas con el tema, finalizándose el ciclo con un cuestionario de evaluación final que permita comprobar el nivel del alumno dentro del proceso de aprendizaje.

Ciclos de Mejora en el Aula (2020). Experiencias de Innovación Docente de la US Esta obra se distribuye con la licencia Creative Commons 
Dentro del modelo metodológico presentado se insertan un conjunto de actividades ideadas para cumplir con el mapa de contenidos propuesto para este ciclo de mejora, presentándose a continuación una serie de cuadros explicativos sobre esta secuencia de tareas.

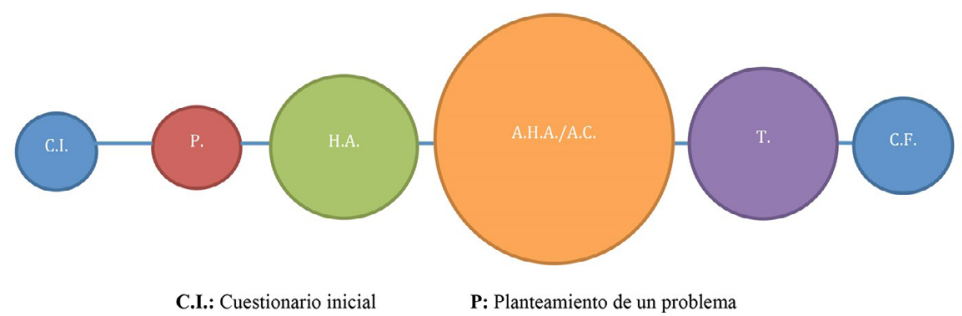

H.A.: Hipótesis alumnos

T.: Teoría

A.H.A.: Análisis histórico-artístico A.C.: Actividad contraste

C.F.: Cuestionario final

Figura 2: Modelo metodológico posible

Tabla 1. Secuencia de actividades del Problema 1

PROBLEMA 1: ¿Qué relación existe entre la arquitectura y los distintos sistemas políticos en Roma?

SESIÓN 1: 2 HORAS.

1

Cuestionario inicial

C.I.

(Previo CIMA2)

La clase se iniciará con la realización de un cuestionario para conocer el grado de conocimiento de los alumnos sobre los contenidos relacionados con los dos problemas que se van a plantear durante el CIMA2. Para ello, deberán responder a una serie de preguntas incluidas en un cuestionario realizado a través de Google Forms. Los alumnos contarán con un total de 20 minutos para responder a preguntas sin contenido académico, intentando partir de su propia experiencia.

Recursos: Cuestionario Google Forms.

\section{2 \\ Planteamiento de un problema}

P.1.

25'

El CIMA2 comenzará contextualizando el primero de los problemas que deberán resolver los alumnos. Los estudiantes asumirán el papel de un historiador del arte que debe solucionar una serie de cuestiones relacionadas con la arquitectura romana. La intención es manejar diversos planteamientos sobre un edificio determinado, pudiendo resolver los problemas que se plantean. La intención es que el alumno asuma que no existe una única vía para llegar a la respuesta o conclusión, debiendo utilizar diversos caminos que le llevará a otras preguntas y, por consiguiente, a un mejor entendimiento del tema.

La primera de las preguntas a resolver es ¿Qué relación existe entre la evolución de la arquitectura y los distintos sistemas políticos en Roma?

Ciclos de Mejora en el Aula (2020). Experiencias de Innovación Docente de la US Esta obra se distribuye con la licencia Creative Commons Reconocimiento-NoComercial-SinObraDerivada Internacional (CC BY-NC-ND 4.0.) 
Recursos: Fotos de diferentes edificios de época romana elegidos al azar. 3 Análisis de textos

H.A.1. 45'

En la clase anterior al inicio del CIMA2 los alumnos recibieron una serie de textos relacionados con la pregunta que se plantea. Cada uno de ellos parte de una hipótesis diferente acerca del problema histórico planteado al inicio de la clase. La intención es crear diferentes grupos conformados por alumnos de distintos niveles que puedan defender cada uno de los planteamientos. El profesor debe intervenir guiando el debate y recomendando algunas pautas para el análisis de los textos. Les indicaré que sería útil que anotasen las conclusiones que vayan saliendo, intentando que vayan avanzando en la materia sin la intervención del profesor.

De este modo podrán aprender a plantear un estado de la cuestión, conociendo las diferentes rutas que existen para llegar a la conclusión del problema.

Recursos: Textos científicos sobre arquitectura romana.

4 Modelos de imágenes

H.A.1. 25'

Los alumnos siguen divididos en varios grupos conformados por distintos niveles. Igualmente, cada uno de los grupos seguirá defendiendo una serie de hipótesis, como en la actividad anterior. En este caso, se trata de ejemplificar las teorías que han defendido con ejemplos prácticos, utilizando para ello imágenes de edificios representativos de la arquitectura romana. Deberán ejemplificar las diferencias o posibles coincidencias existentes entre la arquitectura republicana e imperial. La intención es que puedan reflexionar sobre las posibles soluciones prácticas del problema planteado. El profesor deberá guiar a los estudiantes haciendo diferentes preguntas que pongan en duda sus propuestas.

Recursos: Imágenes de arquitectura romana de diferentes periodos.
5
Teoría
T.1
$25^{\prime}$

Los últimos veinte minutos de clase se dedicarán a explicar algunas nociones teóricas relacionadas con la materia que completen las conclusiones alcanzadas durante las actividades anteriores. El profesor no debe volver a explicar el contenido que ya se ha citado en las actividades anteriores, siendo su deber complementarlo con otras ideas.

Recursos: Imágenes sobre el contenido teórico que se explica.

SESIÓN 2: 2 HORAS

1 Métodos para el análisis histórico

A.H.A.2.

$20^{\prime}$

En el inicio de esta clase, el profesor realizará un breve repaso de los cinco métodos (formalista, iconográfico, atribucionismo, positivismo y sociológico) existentes en la historia del arte para analizar una pieza, intentando ejemplificar su aplicación en algunas imágenes ajenas a la asignatura.

Recursos: Imágenes de distintas obras.

$2 \quad$ Comentario de imágenes

A.H.A.2.// A.C.2.

$50^{\prime}$

Ciclos de Mejora en el Aula (2020). Experiencias de Innovación Docente de la US Esta obra se distribuye con la licencia Creative Commons Reconocimiento-NoComercial-SinObraDerivada 4.0 Internacional (CC BY-NC-ND 4.0.) 
El profesor debe proyectar una serie de imágenes de edificios pertenecientes a distintos periodos de la historia de la arquitectura romana. Aplicando cada uno de los métodos explicados en el apartado anterior, los alumnos deberán aportar diferentes ideas para el comentario de las imágenes. El profesor debe poner en duda sus respuestas para que puedan surgir otras ideas que enriquezcan los comentarios.

Recursos: Imágenes de distintas obras.

\section{3}

Imágenes y fuentes para la historia del

arte

A.H.A.2.// A.C.2.

$50^{\prime}$

Para esta actividad los alumnos deben manejar las dos principales fuentes para la arquitectura romana, el tratado de arquitectura de Vitruvio y la Historia Natural escrita por Plinio el viejo. Ambos textos constituyen las principales fuentes de información sobre la arquitectura romana. El estudiante debe relacionar las imágenes de los edificios de distintos periodos con los textos citados, debiendo identificar cuáles son las recomendaciones publicadas en estos tratados utilizadas por el arquitecto para proyectar el edificio. El estudiante debe primero identificar el edificio, su cronología y su tipología, para después buscar en los distintos capítulos de ambos tratados cuál es la fuente utilizada por los arquitectos. Ello permitirá reconocer el origen teórico de estos edificios, su proceso constructivo y cuestiones relacionadas con la práctica arquitectónica.

El profesor debe poner en duda con diferentes preguntas las ideas que se vayan planteando en el debate conjunto, pudiendo leer otros fragmentos de diferentes textos de la época e incluso aludiendo a otros tratados escritos con posterioridad que partan de los publicados en época romana.

Recursos: Imágenes de distintas obras y textos de Vitruvio, Plinio el Viejo y otros autores romanos.

Tabla 2. Secuencia de actividades del Problema 2

\begin{tabular}{|c|c|c|c|}
\hline \multicolumn{4}{|c|}{$\begin{array}{c}\text { PROBLEMA 2: ¿Cuáles son los antecedentes y consecuentes tipológicos de la } \\
\text { arquitectura y el urbanismo romano? }\end{array}$} \\
\hline \multicolumn{4}{|c|}{ SESIÓN 3: 2 HORAS. } \\
\hline 1 & Planteamiento de un problema & & \\
\hline \multicolumn{4}{|c|}{$\begin{array}{l}\text { El CIMA2 continúa contextualizando el segundo de los problemas que deberán resolver los } \\
\text { alumnos. Los estudiantes asumirán nuevamente el papel de un historiador del arte que } \\
\text { debe resolver una serie de cuestiones relacionadas con la arquitectura y el urbanismo } \\
\text { romano. La intención es manejar diversos planteamientos sobre una ciudad o un edificio } \\
\text { determinado, pudiendo solucionar los problemas que se plantean, relacionados con la } \\
\text { práctica profesional del historiador del arte. La intención es que el alumno asuma que } \\
\text { no existe una única vía para llegar a la respuesta o conclusión, debiendo utilizar diversos } \\
\text { caminos que le llevará a otras preguntas y, por consiguiente, a un mejor entendimiento } \\
\text { del tema. } \\
\text { La primera de las preguntas a resolver es ¿Cuáles son los antecedentes y consecuentes } \\
\text { tipológicos de la arquitectura v el urbanismo romano? }\end{array}$} \\
\hline
\end{tabular}

Ciclos de Mejora en el Aula (2020). Experiencias de Innovación Docente de la US Esta obra se distribuye con la licencia Creative Commons Reconocimiento-NoComercial-SinObraDerivada Internacional (CC BY-NC-ND 4.0.) 
Recursos: Se proyectarán al azar fotografías de diferentes ciudades y edificios de época romana y de periodos posteriores.

\section{2}

Análisis de textos

H.A.3.

$50^{\prime}$

En la clase anterior al inicio del CIMA2 los alumnos recibieron una serie de textos relacionados con la pregunta que se plantea. Cada uno de ellos parte de una hipótesis diferente acerca del problema histórico planteado al inicio de la clase. La intención es crear diferentes grupos conformados por alumnos de distintos niveles que puedan defender cada uno de los planteamientos. El profesor debe intervenir guiando el debate y recomendando algunas pautas para el análisis de los textos. Les indicaré que sería útil que anotasen las conclusiones que vayan saliendo, intentando que vayan avanzando en la materia sin la intervención del profesor.

De este modo podrán aprender a plantear un estado de la cuestión, conociendo las diferentes rutas que existen para llegar a la conclusión del problema.

Recursos: Textos científicos sobre arquitectura y urbanismo anterior y posterior a Roma.

\section{3}

Modelos de imágenes

H.A.3.

20'

Los alumnos siguen divididos en varios grupos conformados por distintos niveles. Igualmente, cada uno de los grupos seguirá defendiendo una serie de hipótesis, como en la actividad anterior. En este caso, se trata de ejemplificar las teorías que han defendido con ejemplos prácticos, utilizando para ello imágenes de edificios representativos anterior y posterior a Roma. Deberán ejemplificar las posibles coincidencias y diferencias existentes entre la arquitectura y el urbanismo anterior y posterior a Roma. La intención es que puedan conocer los antecedentes y modelos previos utilizados por los arquitectos romanos, para diferenciar cuáles han sido los más utilizados. Además, podrán obtener una perspectiva más global de la historia del arte al entender que la arquitectura romana fue la base para otros estilos posteriores. El profesor debe intervenir para guiar el debate, intentando que los alumnos no se limiten a ejemplos de arte antiguo, sino que avancen hasta otras tipologías de arquitectura y urbanismo deudores de Roma como pueden ser el Renacimiento o algunos ejemplos contemporáneos.

Recursos: Imágenes de arquitectura y urbanismo anteriores y posteriores a Roma.

$4 \quad$ A modo de resumen

T.2. 20'

En este caso, la explicación teórica ofrecerá un breve repaso sobre diferentes modelos tipológicos propios de la arquitectura y el urbanismo romano que han sido utilizados por otros arquitectos posteriores en la historia del arte. La intención es dar una visión global de la disciplina, para que el alumno compruebe que no se trata de resolver un problema individual, sino que la historia del arte consiste en relacionar influencias anteriores y posteriores. Esta teoría debe entenderse a modo de conclusión de las actividades desarrolladas anteriormente.

Recursos: Imágenes sobre el contenido teórico que se explica.

SESIÓN 4: 2 HORAS.

\begin{tabular}{l|l}
1 & Estructura de un análisis histórico-artístico
\end{tabular}

A.H.A.4.

$20^{\prime}$

Ciclos de Mejora en el Aula (2020). Experiencias de Innovación Docente de la US

Esta obra se distribuye con la licencia Creative Commons

Reconocimiento-NoComercial-SinObraDerivada

Internacional (CC BY-NC-ND 4.0.) 
En el inicio de esta clase, el profesor explicará la estructura ideal de un comentario histórico-artístico. Esta formación permitirá complementar el contenido de lo explicado en el mismo apartado durante la sesión 2, con el interés de que el estudiante pueda mejorar en la realización de comentarios histórico-artísticos.

Recursos: Modelo de comentario histórico-artístico.

\section{2}

Comentario de imágenes

A.H.A.4.// A.C.4.

40'

El profesor debe proyectar una serie de imágenes de edificios y ciudades pertenecientes a distintos periodos de la historia de la historia del arte. Aplicando las pautas del análisis histórico-artístico, los alumnos deberán aportar diferentes ideas para el comentario de las imágenes en las que relacionen las obras con los modelos y tipologías arquitectónicas y urbanísticas de época romana. Se proyectarán diferentes imágenes de edificios que tengan similitudes o diferencias con los principales modelos romanos para que el alumno los identifique. El profesor debe poner en duda sus respuestas para que puedan surgir otras ideas que enriquezcan los comentarios.

Recursos: Imágenes de distintas obras.

\section{3}

Imágenes y fuentes para la historia del arte

A.H.A.4./I

A.C.4.

40'

Para esta actividad los alumnos deben manejar los tratados de arquitectura de Vitruvio y otros escritos con posterioridad durante la Edad Media, el Renacimiento o la Ilustración, como son los de Villard de Honnecourt, Serlio, Palladio o Piranessi. Estos textos constituyen las principales fuentes de información sobre la arquitectura romana y su proyección en otros estilos de las historia del arte. El estudiante debe relacionar las imágenes de los edificios de distintos periodos con los textos citados, debiendo identificar cuáles son las recomendaciones publicadas en estos tratados que parten de la arquitectura romana. El estudiante debe primero identificar el edificio, su cronología y su tipología, para después buscar en los distintos capítulos de ambos tratados cuál es la fuente romana utilizada por los arquitectos. Ello permitirá reconocer el origen teórico de estos edificios, entendiendo la historia del arte como un conjunto de relaciones e influencias entre distintos periodos, abriendo la capacidad de análisis de los estudiantes.

El profesor debe poner en duda con diferentes preguntas las ideas que se vayan planteando en el debate conjunto, pudiendo leer otros fragmentos de diferentes textos de la época e incluso aludiendo a otros tratados escritos con posterioridad que partan de los publicados en época romana.

Recursos: Imágenes de distintas ciudades y edificios anteriores y posteriores a Roma.

\section{4}

Cuestionario final

C.F.

La clase concluirá con la realización de un cuestionario para conocer el grado de conocimiento alcanzado por los alumnos sobre los contenidos relacionados con los dos problemas planteados durante el CIMA2. Para ello, deberán responder a una serie de preguntas incluidas en un cuestionario realizado a través de Google Forms. Los alumnos contarán con un total de 20 minutos para responder a preguntas sin contenido académico, intentando partir de su propia experiencia.

Recursos: Cuestionario Google Forms.

Ciclos de Mejora en el Aula (2020). Experiencias de Innovación Docente de la US Esta obra se distribuye con la licencia Creative Commons Reconocimiento-NoComercial-SinObraDerivada Internacional (CC BY-NC-ND 4.0.) 
La realización de un cuestionario inicial para conocer el nivel del alumno es una herramienta útil para la elección de los contenidos que se desarrollarán durante el ciclo de mejora. La intención es preguntar sobre una serie de cuestiones relacionadas con dicho contenido, debiendo formularse cuestiones que permitan responder de acuerdo a la experiencia del propio alumno, fomentando una capacidad de respuesta que excluya un contenido meramente académico. El mismo conjunto de preguntas volverán a realizarse tras la finalización del ciclo de mejora, debiéndose analizar las respuestas de los alumnos para conocer el grado de aprendizaje adquirido.

El formulario que a continuación se presenta tiene como principal interés plantear una serie de cuestiones que os permitan reflexionar sobre asuntos relacionados con la arquitectura romana, como uno de los temas fundamentales de la asignatura. Para ello, intentemos ponernos en la piel de un arquitecto que debe enfrentarse a los problemas que se describen, reflexionando sobre posibles soluciones. Se trata de un simple cuestionario no vinculante, por lo que debéis responder con vuestra experiencia personal. El cuestionario debe ser anónimo, por lo que en la primera de las preguntas debéis poner un mote. Posteriormente, se deberá explicar qué se entiende por Arquitectura, cuáles son las cinco cosas más importantes que deben saber los arquitectos, cuáles son los requisitos más importantes que debería tener una ciudad ideal, de dónde tomaría las medidas para la erección de un templo, cómo representarías en una ciudad y en sus edificios el cambio de sistema político entre República e Imperio, cuáles son los elementos urbanísticos de la ciudad actual que ya existían en una urbe romana y qué importancia tiene el correcto uso de los órdenes de arquitectura, la distribución de los espacios y la orientación de un edificio.

Ciclos de Mejora en el Aula (2020). Experiencias de Innovación Docente de la US Esta obra se distribuye con la licencia Creative Commons 


\section{Aplicación del CIMA}

\section{Desarrollo de las sesiones}

De entre las nuevas herramientas utilizadas para el diseño de la metodología, contenidos y evaluación de este ciclo de mejora, cabe destacar la realización de un diario de sesiones en el que se han descrito los acontecimientos vividos. Nuevamente, la aplicación de este método ha servido para organizar de manera escrita un conjunto de problemas relacionados con el desarrollo de las clases, permitiendo poner el foco de atención en la mejora de estos asuntos de cara al diseño de un futuro CIMA. En este diario, se ha podido comprobar que a lo largo de las sesiones los alumnos han interactuado de manera extraordinaria en el cumplimiento de las tareas, ejerciendo como protagonistas del proceso de aprendizaje y limitando la participación del profesor, quien se ocupaba de establecer una serie de pautas a modo de guía.

La primera de las sesiones se inició presentando el contexto sobre el que los alumnos iban a trabajar durante el ciclo de mejora, procediéndose a continuación a la división de la clase en cuatro grupos y al análisis del primero de los textos. La organización de un debate sobre las diferentes hipótesis planteadas por los historiadores acerca del primero de los problemas resultó enriquecedora para el avance en el proceso de aprendizaje. Igualmente novedosa fue la utilización de imágenes propios del alumnado como ejemplo de sus interpretaciones, alterando el orden tradicional de la docencia en la que es el profesor quien elige las imágenes que se analizarán en clase. Precisamente con la intención de ahondar en estos análisis, en la segunda sesión se explicaron los modos de aplicación de los métodos de investigación de la Historia del Arte, correspondiéndole a los alumnos aplicarlos en ejemplos elegidos por ellos. 
En la tercera de las sesiones se planteó el segundo de los problemas que ocuparían este ciclo de mejora, consistente en la investigación de los antecedentes y consecuentes tipológicos de la arquitectura romana. Los alumnos presentaron una cierta inseguridad, pues se trataba de un planteamiento que se escapaba del sentido diacrónico con el que tradicionalmente se explica la Historia del Arte. Precisamente por esta causa, fueron numerosas las preguntas complementarias que surgieron en esta primera sesión, enriqueciendo las líneas de investigación sobre el problema principal. El análisis de varios textos relacionados con la materia propició un debate sobre los diferentes planteamientos propuestos por los investigadores defendidos por distintos grupos.

La última de las sesiones tenía como objetivo complementar a la sesión dos, donde las actividades estaban centradas en la aplicación de los métodos histórico-artísticos. En este caso, los alumnos fueron realizando algunos comentarios relacionados con la estructura de un análisis de una obra de arte, incluyendo los modos de citar, redactar o contextualizar un problema. Por último, tras realizar el cuestionario final, pude comprobar como un alto porcentaje del alumnado se mostraba agradecido por el interés en mejorar la docencia y la práctica profesional como futuros historiadores del arte.

Por tanto, el desarrollo de las sesiones ha sido positivo en un amplio porcentaje de las actividades propuestas, a pesar de ciertos desajustes relacionados con el tiempo que deben ser mejorados en futuros ciclos de mejora. La aplicación de las actividades propuestas para las sesiones ha sido positiva, sobre todo porque se han hablado de conceptos y métodos diferentes a los que en principio son tradicionales para esta asignatura. Todo ello ha permitido entender los contenidos desde una perspectiva más general, pues los alumnos han tenido la oportunidad de relacionar conceptos como práctica fundamental del historiador del arte.

Ciclos de Mejora en el Aula (2020). Experiencias de Innovación Docente de la US Esta obra se distribuye con la licencia Creative Commons 
La realización de un cuestionario en el que los estudiantes debían responder preguntas relacionadas con el contenido que se iba a desarrollar durante el ciclo de mejora fue la actividad inicial y final del ciclo de mejora. A partir de los resultados obtenidos y siguiendo la fórmula desarrollada por diferentes investigadores, se han creado una serie de esquemas a modo de escaleras de niveles que permiten organizar el contenido en función de su dificultad. Ello permite situar a los alumnos según el grado de conocimiento alcanzado tanto al inicio como al final del CIMA, pudiendo obtener conclusiones relativas al proceso de aprendizaje. Aunque hayan sido siete las preguntas que formaban parte del cuestionario inicial y final, se presentan a continuación tres casos a modo de ejemplo.

En la primera pregunta del cuestionario se pedía que explicasen con sus propias palabras qué entendían por Arquitectura. Los diferentes resultados obtenidos entre el cuestionario inicial y final permiten entender que el proceso de aprendizaje ha sido satisfactorio. En este caso, cabe destacar que hasta un 70\% del alumnado finalizó el ciclo de mejora en el último peldaño de la escalera, superando obstáculos como la falta de integración del edificio en su contexto o el entendimiento de la Arquitectura como una capacidad innata para la proyección y diseño de edificios. En proporción, la disminución del primer y el tercer peldaño es una buena noticia, permitiendo entender que se han superado los objetivos propuestos antes de iniciar el ciclo de mejora.

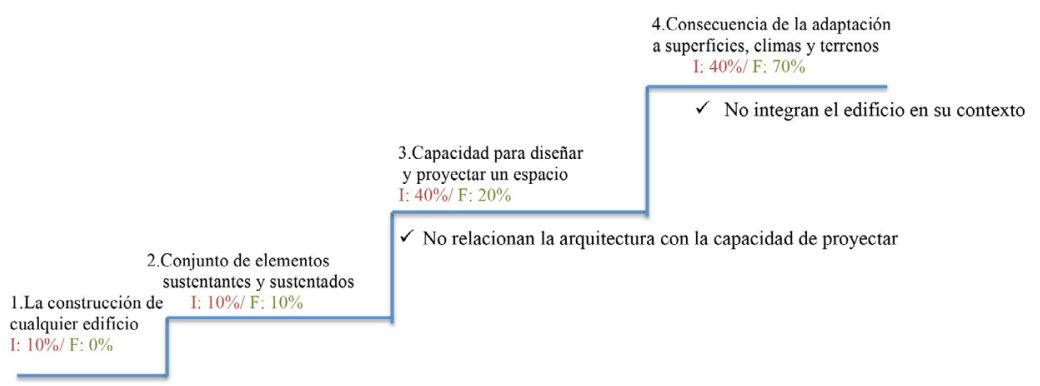

Figura 3. Escalera de aprendizaje de la pregunta no 1 del cuestionario

Ciclos de Mejora en el Aula (2020). Experiencias de Innovación Docente de la US Esta obra se distribuye con la licencia Creative Commons 
Con la segunda de las cuestiones se pretendía saber, en base a la experiencia del alumnado, cuáles son las cinco cosas más importantes que debe conocer un arquitecto. Así, llama la atención como un 10\% del alumnado respondió cuestiones relacionadas con la historia de la arquitectura, obviando otros asuntos relacionados con la técnica o la ciencia aplicada a esta disciplina. Un alto porcentaje apuntó hacia asuntos relacionados con los materiales o la decoración, manteniéndose en un número pareja en el cuestionario final en el tercer peldaño. Finalmente, en el cuarto escalón se situaban alumnos que respondieron asuntos relacionados con la teoría, el dibujo y las matemáticas, superando obstáculos relacionados con las ciencias, el diseño y la proyección de espacios y pasando del $20 \%$ inicial al $40 \%$ en el cuestionario final.

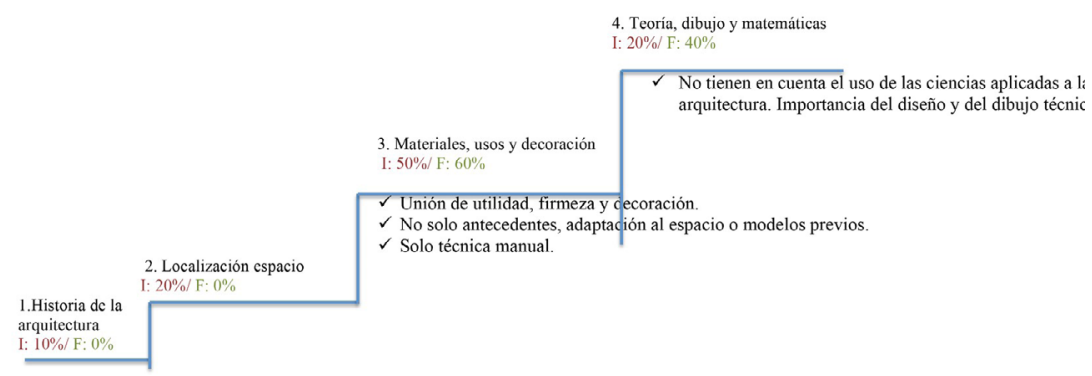

Figura 4. Escalera de aprendizaje de la pregunta no 2 del cuestionario

En la tercera de las preguntas se pedía que respondieran, partiendo de su propio juicio, sobre los requisitos más importantes que debía tener una ciudad ideal. En este sentido, llama la atención como un alto porcentaje del alumnado aludió inicialmente a asuntos relacionados con el agua y las materias primas, pasando en el cuestionario final a tan solo el $10 \%$ del global. También es destacable la acumulación del $50 \%$ del alumnado en el tercer peldaño durante el cuestionario final, haciendo referencia al trazado regular de la ciudad y superando obstáculos en los Ciclos de Mejora en el Aula (2020). Experiencias de Innovación Docente de la US 
que no se tenía en cuenta la comodidad y los diferentes usos de las partes de una ciudad. Finalmente, en la parte superior de la escalera, se pasó de un $10 \%$ a un $30 \%$ del alumnado que relacionó una ciudad ideal con la necesidad de construir edificios representativos que determinen la imagen del conjunto, demostrando un conocimiento de la experiencia histórica y del modo de representación de los poderes sociales, políticos y económicos en el urbanismo.

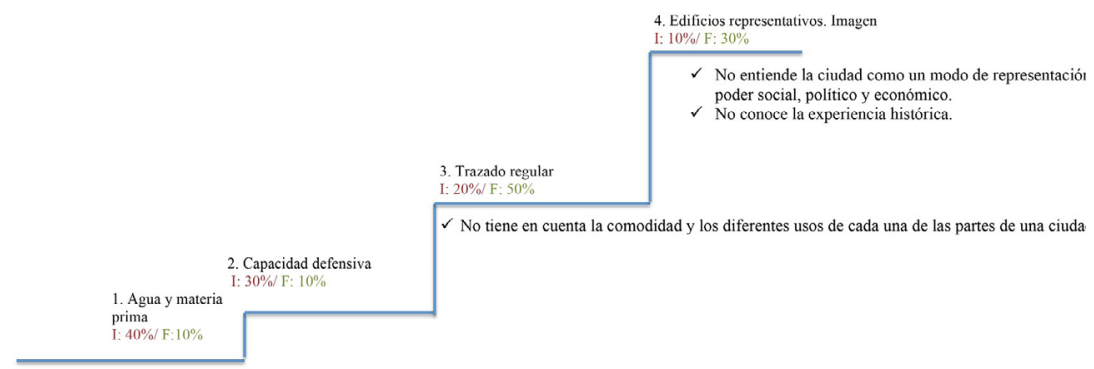

Figura 5. Escalera de aprendizaje de la pregunta no 3 del cuestionario

Cuadro de evolución por estudiante según los datos del cuestionario

Con la tabla que se presenta se intenta mostrar la evolución de los estudiantes según los datos obtenidos de los cuestionarios iniciales y finales. Para ello, se han insertado las respuestas de diez alumnos en diferentes columnas, diferenciándolas entre iniciales y finales. Todo ello permite ofrecer una visión general del avance del alumno en el proceso de aprendizaje, comprobando si ha logrado superar determinados obstáculos y conseguir alcanzar el peldaño superior como objetivo principal en el ciclo de mejora.

Ciclos de Mejora en el Aula (2020). Experiencias de Innovación Docente de la US Esta obra se distribuye con la licencia Creative Commons 


\begin{tabular}{|c|c|c|c|c|c|c|c|c|c|c|c|c|c|c|}
\hline \multirow[b]{2}{*}{ ESTUDIANTE } & \multicolumn{14}{|c|}{ PREGUNTAS } \\
\hline & 11 & $1 F$ & $2 I$ & $2 F$ & 31 & $3 F$ & $4 I$ & $4 F$ & 51 & $5 F$ & 61 & $6 F$ & 71 & $7 F$ \\
\hline 1 & 4 & 4 & 4 & 4 & 1 & 1 & 1 & 1 & 3 & 3 & 4 & 4 & 3 & 3 \\
\hline 2 & 4 & 4 & 3 & 4 & 2 & 3 & 2 & 3 & 2 & 2 & 3 & 3 & 2 & 2 \\
\hline 3 & 3 & 3 & 3 & 3 & 1 & 2 & 2 & 3 & 2 & 2 & 1 & 3 & 1 & 1 \\
\hline 4 & 2 & 2 & 3 & 3 & 2 & 3 & 1 & 2 & 1 & 2 & 4 & 4 & 1 & 2 \\
\hline 5 & 4 & 4 & 2 & 3 & 2 & 3 & 1 & 3 & 3 & 3 & 3 & 4 & 2 & 3 \\
\hline 6 & 3 & 3 & 2 & 3 & 3 & 4 & 3 & 4 & 2 & 2 & 1 & 3 & 2 & 3 \\
\hline 7 & 4 & 4 & 3 & 3 & 4 & 4 & 3 & 4 & 3 & 3 & 4 & 4 & 1 & 2 \\
\hline 8 & 3 & 4 & 4 & 4 & 1 & 3 & 4 & 4 & 2 & 2 & 2 & 3 & 2 & 2 \\
\hline 9 & 3 & 4 & 3 & 4 & 3 & 4 & 1 & 3 & 1 & 2 & 3 & 4 & 2 & 2 \\
\hline 10 & 1 & 4 & 1 & 3 & 1 & 3 & 2 & 4 & 1 & 1 & 3 & 4 & 1 & 2 \\
\hline
\end{tabular}

Tabla 3. Cuadro de evolución por estudiante en relación con el cuestionario

\section{Evaluación del CIMA}

\section{Cuestiones a mantener y cambios a introducir para un futuro CIMA}

Tras la experiencia de este ciclo de mejora, adaptado a un total de 8 horas, considero que el modelo metodológico ha resultado ser enormemente efectivo para el aprendizaje del alumnado mediante una fórmula que promueva la investigación. La posibilidad de crear debates ha generado un ambiente inmejorable para el avance en el proceso de aprendizaje, incitando a los alumnos a responder cuestiones que debían rebatir. Igualmente, considero que la realización de un cuestionario tanto al inicio como al final del ciclo de mejora permite obtener un diagnóstico general de la evolución del estudiante, siendo un método útil que se debería implantar en la programación de la asignatura.

Por otro lado, la experiencia obtenida permite igualmente reconocer que es necesario introducir algunos

Ciclos de Mejora en el Aula (2020). Experiencias de Innovación Docente de la US Esta obra se distribuye con la licencia Creative Commons 
cambios para futuros ciclos de mejora. En relación a la metodología, reduciría el tiempo dedicado a las actividades teóricas, pues suponen una vuelta al modelo tradicional y genera un cierto detenimiento del ritmo de la clase alcanzado gracias a otras actividades. En relación al contenido, sería conveniente reducir el mapa de contenido a conceptos más concretos que permitan focalizar la atención del estudiante de manera más precisa.

\section{Aspectos que se pretenden incorporar a toda la práctica docente}

La programación de la asignatura a través de un listado de actividades es una herramienta enormemente eficaz para mejorar la organización de las clases, pues permite dividir el tiempo con mayor certeza y evita improvisaciones que desvirtúen la atención del alumno o no permita alcanzar los objetivos propuestos para el ciclo de mejora. Igualmente, considero que la realización de un diario de sesiones es positiva para conocer posibles fallos que se deben mejorar en el futuro, siendo importante reflexionar sobre la sesión y escribir algunas notas al respecto. Finalmente, a partir de este ciclo de mejora recomiendo preparar las sesiones realizando el recorrido que el alumno deberá practicar desde un punto inicial hasta lograr responder con la mayor precisión posible a la pregunta planteada. Ello permitirá entender mejor su proceso de aprendizaje y ayudarle a alcanzar el objetivo.

\section{Principios didácticos argumentados}

Proceso de aprendizaje del alumno:

- Priorizar la organización de la docencia en base a las necesidades del alumnado, pues no siempre se ha tenido en cuenta esos condicionantes para fomentar el avance en el proceso de aprendizaje.

- Fomentar la participación y la interacción alumno/ alumno y alumno/profesor, abandonando el modelo 
tradicional en el que el profesor es el sujeto pensando y el alumno es un receptor pasivo.

Contenidos de la enseñanza:

- Mejorar en la organización de los contenidos de la asignatura, no centrándonos únicamente en la transmisión de datos que los alumnos deben memorizar, sino ofreciendo otros contenidos conceptuales o procedimentales que faciliten la resolución del problema.

- Fomentar los contenidos actitudinales no como un complemento a los datos o a los conceptuales, sino asumiendo su papel importante como parte del contenido global de la asignatura.

- Organizar los contenidos de la asignatura partiendo de un problema previo que se debe resolver y realizando previamente el proceso de aprendizaje que el alumno hará para obtener la solución a dicha cuestión.

- Utilizar mapas que faciliten la comprensión de los diferentes contenidos de la asignatura, lo que mejora su comprensión y la presentación de los contenidos estructurales.

Metodología y evaluación:

- Incluir una serie de encuestas iniciales que permitan diagnosticar el nivel en el que el alumno se encuentra antes del proceso de aprendizaje.

- Utilizar escaleras de aprendizaje que permitan desarrollar visualmente los diferentes niveles dentro del proceso de aprendizaje, pues facilitan enormemente la organización de los contenidos y permiten detectar posibles carencias.

- Realizar diarios de sesiones que puedan ser consultados durante la preparación de próximas sesiones o cursos, pues son una herramienta importante para recordar posibles mejoras que se apliquen en otros ciclos. 
Palabras claves: Arte antiguo y medieval en Andalucía, Grado en Historia del Arte, Docencia universitaria, Experimentación docente universitaria.

Keywords: Ancient and medieval art in Andalusia, Art History Studies, University teaching, University teaching experimentation.

\section{Referencias bibliográficas}

Bain, K. (2007). Lo que hacen los mejores profesores universitarios. Valencia: Universitat de Valencia.

De Alba, N. y Porlán, R. (2017). La metodología de enseñanza. En R. Porlán. Enseñanza universitaria. Cómo mejorarla (pp. 37-54). Madrid: Morata.

Finkel, D. (2008). Dar clașe con la boca cerrada. Valencia: Universitat de Valencia.

García Díaz, E., Porlán, R. y Navarro, E. (2017). Los fines y los contenidos de enseñanza. En R. Porlán. Enseñanza universitaria. Cómo mejorarla. Madrid: Morata.

Ciclos de Mejora en el Aula (2020). Experiencias de Innovación Docente de la US Esta obra se distribuye con la licencia Creative Commons 